\title{
Factors Affecting Perioperative Blood Transfusion Applications in a University Hospital
}

Etik Kurul Onayı: Bülent Ecevit Üniversitesi Klinik Araştırmalar Etik Kurulu onayı alınmış$\operatorname{tir}(28 / 02 / 2018 / 05)$.

Çıkar çatışması: Yoktur

Finansal destek: Yoktur

Hasta onamı: Çalışma retrospektifti.

öz

Amaç: Kan kullanımının azaltılmasına yönelik yöntemlere rağmen, transfüzyon uygulamalarında hâlen kurumsal ve kişisel farklııklar mevcuttur. Çalışmamızın amacı, bir üniversite hastanesi olan kurumumuzdaki peroperatif transfüzyon uygulamalarını etkileyen faktörleri ve transfüzyon sıklığını belirlemektir.

Yöntem: Retrospektif yapılan çalışma, Ocak 2017-Haziran 2017 tarihleri arasında opere olan ve peroperatif kan transfüzyonu yapılan 245 hastayla tamamlandı. Hastaların demografik özelliklerinin, peroperatif $\mathrm{Hb}$ değerlerinin, cerrahi prosedürün/bölümün/sürenin, ASA skorunun, anestezi yönteminin, mevcut hematolojik patoloji varlığının, preoperatif antikoagülan kullanımının ve ek hastalık sayısının peroperatif transfüzyon gereksinimini belirlemedeki etkinliği değerlendirildi. İstatistiksel değerlendirme sonucu $p<0.05$ anlamlı kabul edildi.

Bulgular: Hastaların ortalama yası $58.09+16.11$ yıl ve cerrahi süresi $226.17 \pm 125.59 \mathrm{dk}$ olarak saptandı. Hastalarımızın preoperatif muayenesinde \%37.1 (n=91)'inin anemik olduğu, \%50.6 (n=124)'sının antikoagülan ilaç kullandığı ve \%78 (n=191)'inin de ek hastalığı olduğu gözlendi. Anemisi olan hastaların transfüzyon gereksiniminin olmayanlara göre daha fazla olduğu ve bu hastaların 40 (\%43.9)'ına preoperatif, 28 (\%30.8)'ine intraoperatif ve 78 (\%85.7)'ine de postoperatif dönemde transfüzyon yapıldığı belirlendi. Toplamda transfüzyon sıklı̆ımız preoperatif \%20.8, intraoperatif \%41.6 ve postoperatif dönemde de \%92.2 idi. Preoperatif transfüzyonlarının preoperatif-Hb seviyesi ortalaması $10.15 \pm 1.86 \mathrm{~g} / \mathrm{dL}$ olan, kadın cinsiyet, ASA 2-3 risk grubu, anemi tanısı olan ve preoperatif-Hb değeri 7.1-12.9 g/dL olanlarda; intraoperatif transfüzyonlarının intraoperatif- $\mathrm{Hb}$ seviyesi ortalaması $12.23 \pm 2.2 \mathrm{~g} / \mathrm{dL}$ olan, ileri yas, erkek cinsiyet, uzun süren cerrahiler, KVC ve ortopedi cerrahileri, ASA 3-4 risk grubu, genel anestezi uygulanan, anemi tanısı olan, antikoagülan ilaç kullanımı ve yandaş hastalığı olan ve intraoperatif-Hb değeri 7.1-12.9 g/dL olanlarda ve postoperatif transfüzyonların ise elektif şartlarda, anemi tanısı olan ve postoperatif-Hb değeri 7.1-12.9 g/dL olanlarda daha fazla yapıldığı saptandı. Sonuç: Transfüzyon kararı birçok parametreyi değerlendirerek alınması gereken multidisipliner bir karardır. Transfüzyon kararının büyük oranda ilgili hekim tarafından verildiği, hastaların \%20.8'ine preoperatif, \%41.6'üne intraoperatif ve \%92.2'sine postoperatif dönemlerde transfüzyon yapıldığı izlendi. Transfüzyon protokollerinin tüm hekimler tarafından yine gözden geçirilmesinin önlenebilir transfüzyonların azaltılmasında önemli bir role sahip olabileceği ve transfüzyon uygulamasında davranış değişikliğinin gereksiz transfüzyonlardan kaçınmamıza ve böylece hasta güvenliği açısından da daha az risk almamıza neden olacağı kanısındayız.

Anahtar kelimeler: anemi, peroperatif kan transfüzyonu, risk faktörleri

ABSTRACT

Objective: In spite of methods to reduce blood use, there are still institutional and personal differences in transfusion applications. The aim of this study was to determine the factors affecting the perioperative transfusion procedures and the frequency of transfusions in our institution, a university hospital.

Methods: The retrospective study was completed with 245 patients who were operated underwent and received perioperative blood transfusions between January 2017 and June 2017. The efficacy of the patients' demographic characteristics, perioperative $\mathrm{Hb}$ values, surgical procedure-part-time, ASA scores, anesthesia method, presence of existing hematological pathology, preoperative anticoagulant use and number of additional diseases were evaluated in determining the need for peroperative transfusion. $p<0.05$ was considered statistically significant.

Results: The mean age of the patients was $58.09 \pm 16.11$ years and the duration of surgery was $226.17 \pm 125.59$ minutes. In the preoperative examination of our patients, it was observed that $37.1 \%(n=91)$ of them were anemic, $50.6 \%(n=124)$ of them were using anticoagulant drugs and $78 \%(n=191)$ of them had additional disease. It was determined that patients with anemia had more frequently required transfusions than those without anemia and these patients had received preoperative ( $n=40: 43.9 \%)$, intraoperative $(n=28: 30.8 \%)$ and 78 postoperative $(n=78: 85.7 \%)$ transfusions. We performed our transfusions during preoperative (20.8\%), intraoperative $(41.6 \%)$ and postoperative $(92.2 \%)$ period in respective frequencies. Preoperative transfusions were more frequently performed in patients with mean preoperative $\mathrm{Hb}$ level of $10.15+1.86 \mathrm{gr} / \mathrm{dL}$ female cases in ASA 2-3 risk group and diagnosed with anemia. Intraoperative transfusions were more frequently performed in advanced-age anemic male patients in ASA 3-4 risk Intraoperative transfusions were more frequently performed in advanced-age anemic male patients in ASA 3-4 risk
group with intraoperative- $\mathrm{Hb}$ level of $12.23 \pm 2.2 \mathrm{~g} / \mathrm{dL}$, comorbidities and undergoing long-lasting surgeries, CVS and orthopedic surgeries under general anesthesia, and anticoagulant drug users postoperative transfusions were more frequently performed under elective conditions in patients with diagnosis of anemia and postoperative-Hb value of 7.1-12.9 gr/dL.

Conclusion: Transfusion decision is a multidisciplinary decision that needs to be made by evaluating many parameters. It was observed that the transfusion decision was made mostly by the attending physician, and pre-intra-, and postoperative transfusions were performed in. 20.8\%, 41.6, and $92.2 \%$ of of the patients We believe that the review of transfusion protocols by all physicians may have an important role in reducing preventable transfusions, and that behavioral changes in transfusion practice will avoid unnecessary transfusions and thus lower risk for patient safety.

Keywords: anemia, peroperative blood transfusion, risk factors
Alındığı tarih: 02.08.2019

Kabul tarihi: 23.10 .2019

Yayın tarihi: 31.12 .2019

Gamze Küçükosman

Bülent Ecevit Üniversitesi Tıp Fakültesi Anesteziyoloji ve Reanimasyon ABD Zonguldak - Türkiye gamzebeu@gmail.com ORCID: 0000-0001-5224-0258

M. E. Dinçer 0000-0001-8367-8762

H. Ayoğlu 0000-0002-6869-5932

Bülent Ecevit Üniversitesi Tıp Fakültesi Anesteziyoloji ve Reanimasyon $A B D$ Zonguldak - Türkiye

B. Akkaya 0000-0002-4571-9065 Bülent Ecevit Üniversitesi Tıp Fakültesi Hastanesi Kan Transfüzyon Komitesi Hemovijilans Hemşiresi Zonguldak - Türkiye

(C) Telif hakkı Göğüs Kalp Damar Anestezi ve Yoğun Bakım Derneği'ne aittir. Logos Tıp Yayıncılık tarafindan yayınlanmaktadır. Bu dergide yayınlanan bütün makaleler Creative Commons Atff-Gayri Ticari 4.0 Uluslararası Lisansı ile lisanslanmıştır. 


\section{Giriş}

Kan transfüzyonu terimi; hastaya kan bileşenlerinin (tam kan, eritrosit konsantresi, taze donmuş plazma, trombosit konsantresi, kriyopresipitat) ve koagülasyon faktör konsantrelerinin verilmesini içerir [1]. Cerrahi hastalarında kan transfüzyonunu azaltmaya yönelik teknik ve farmakolojik birçok yöntem uygulanmasına rağmen, transfüzyonun ne zaman yapılacağı konusunda fikir birliği olmayıp, transfüzyon uygulamalarında hâlen kurumsal ve kişisel farklılar mevcuttur ${ }^{[2,3]}$. On Avrupa Birliği ülkesinde transfüzyon yaklaşımları açısından 43 eğitim hastanesinin karşılaştırıldığı SAnGUIS çalışması, kan transfüzyonunu sorgulayan önemli çalışmalardan biridir. Bu çalışmada, standart ameliyatlarda ve homojen hasta gruplarında hastaneler arasında kan transfüzyon oranlarının son derece değişkenlik gösterdiği belirtilmiştir. Örneğin koroner arter baypas greftleme ameliyatlarında bu oranın \%0-96, total kalça protezlerinde \%0-100 arasında bulunmuş olması aynı özellikteki hastalarda aynı ameliyat için bazı merkezlerde hiç kan kullanılmazken, diğerinde neredeyse her zaman kan kullanıldığını göstermiştir ${ }^{[4]}$. Bu da "Kan transfüzyonu hastaya göre değil, hekime göre gerçekleşen bir uygulamadır." yorumuna yol açmıştır ${ }^{[5]}$.

Dünya Sağlık Örgütü (WHO) anemiyi hemoglobin $(\mathrm{Hb})$ konsantrasyonunu erkekler için $<13 \mathrm{~g} / \mathrm{dL}$, gebe olmayan kadınlar için $<12 \mathrm{~g} / \mathrm{dL}$ ve hamile için $<11 \mathrm{~g} /$ dL olarak tanımlamaktadır ${ }^{[6]}$. Son zamanlarda cerrahi hastalarında kan kullanımını optimize etmeye büyük önem verilmiştir. Kılavuzlar, çoğu hasta için 6-7 g/ dL'lik $\mathrm{Hb}$ veya yüksek riskli hastalar için 7-10 g/dL'lik daha yüksek bir Hb konsantrasyonunun transfüzyon için uygun sınırlar olduğunu belirtmektedir. Literatürde belirtilen bu $\mathrm{Hb}$ konsantrasyonları kabul edilebilir en düşük hemoglobini tanımlamaya çalışsa da transfüzyon uygulamaları izole bir laboratuvar ölçümünden ( $\mathrm{Hb}$ ve hematokrit değerleri) ziyade çoklu fizyolojik parametrelerin (taşikardi, hipotansiyon, dispne, ST segment değişiklikleri, aritmi, mental durum, oligüri) ve ileri laboratuvar yöntemlerinin (oksijen ekstraksiyon oranında artış, transözofajiyal ekokardiyografide yeni başlangıçlı duvar hareket anormallikleri, kardiyak output ve arteriel kanın oksijen miktarı, venöz oksijen saturasyonu, baz açığı, laktat düzeyi, gastrik intramukozal $\mathrm{pH}$, sublingual mikrosirkülasyon vb.) dikkate alınarak yapılması gerektiğinden standartlaştırılmasının zor olduğu bilinmektedir ${ }^{[7-16]}$.

Kan bileşenlerinin peroperatif kullanımının optimize edilmesi; hasta güvenliği, maliyet kontrolü ve genellikle yetersiz sağlanan değerli bir kaynağın korunmasını sağlaması açısından doğrudan etkileri olan zor ama önemli bir iştir. Kan bileşenlerinin kullanımını çok çeşitli cerrahi özellikler ve prosedürler sunan büyük bir kurumda belirli bir prosedür ile takip etmenin zor olduğu ve doktorlar, merkezler ve ülkeler arasında farklılık gösterdiği bildirilmiştir [3,4,17-20]. Biz de çalışmamızı bir üniversite hastanesi olan kurumumuzdaki peroperatif kan transfüzyon uygulamalarını etkileyen faktörleri ve kan transfüzyon sıklığını belirlemek amacıyla planlandık.

\section{GEREÇ ve YÖNTEM}

Hastane Etik Kurul onayı alındıktan sonra, 3. basamak üniversitesi hastanesinde Ocak 2017-Haziran 2017 tarihleri arasında opere olan, ameliyat öncesi 24 saat (s) içinde, intraoperatif ve postoperatif ilk 24 s'te kan transfüzyonu yapılan hastaların kaydına ulaşıldı. Çalışma verileri hastane otomasyon sisteminin retrospektif incelenmesiyle elde edildi. Masif transfüzyon (hastanın toplam kan volümünün 24 saatten kısa bir süre içerisinde transfüze edilmesi işlemidir [1]) adayı, 18 yaşından küçük, kanser hastaları ve verilerinde eksiklik olan hastalar çalışma dışı bırakıldı. Veriler standart protokole ve veri kayıt formuna uygun olarak kaydedildi. Hastanemizde kan transfüzyon kararı hastayı preoperatif ve postoperatif dönemlerde primer olarak takip eden hekim tarafından verilirken, intraoperatif dönemde anestezist ve cerrahi iş birliğiyle verilmektedir. Preoperatif $\mathrm{Hb}$ (preop- $\mathrm{Hb}$ ) düzeyi, ameliyat öncesi ölçülen son $\mathrm{Hb}$ değeri olarak tanımlandı. İntraoperatif $\mathrm{Hb}$ (intraop$\mathrm{Hb}$ ) düzeyi; intraop-Hb değeri ölçülmeyen hastalar 
için preoperatif ölçülen son $\mathrm{Hb}$ değeri olarak kabul edilirken, intraop-Hb değeri ölçülen hastalar için ise kan transfüzyonu öncesi ölçülen $\mathrm{Hb}$ değeri olarak tanımlandı. Postoperatif $\mathrm{Hb}$ (postop-Hb) düzeyi ise cerrahi sonrası serviste ilk ölçülen $\mathrm{Hb}$ değeri olarak belirlendi. Çalışmamızda Muñoz ve ark.'nın ${ }^{[21]}$ da belirttiği gibi cinsiyetten bağımsız olarak $\mathrm{Hb}<13 \mathrm{~g} / \mathrm{dL}$ değeri "anemi" olarak kabul edildi.

Arşiv kayıtlarından, hastaların demografik özellikleri (yaş, cinsiyet), cerrahi bölümü [kalp-damar cerrahisi (KVC), jinekoloji, ortopedi, genel cerrahi, obstetrik, diğer cerrahiler (beyin ve göğüs cerrahisi)], cerrahi prosedürü (acil, elektif), Amerikan Anesteziyologlar Derneği (ASA) skoru (1-4), anestezi yöntemi (1: genel, 2: rejyonal), cerrahi süresi, peroperatif $\mathrm{Hb}$ düzeyleri (1: $\mathrm{Hb}: \leq 7 \mathrm{~g} / \mathrm{dL}, 2: \mathrm{Hb}: 7.1-12.9 \mathrm{~g} / \mathrm{dL}, 3: \mathrm{Hb} \geq 13 \mathrm{~g} / \mathrm{dL}$ ), preoperatif hematolojik patoloji varlığı [0: yok, 1 : anemi, 2: diğerleri (pansitopeni, trombositopeni)], preoperatif antikoagülan kullanımı (var, yok), mevcut cerrahi patoloji hariç eşlik eden hastalık sayısı (0: yok, 1: 1 hastalık, 2: iki hastalık, 3: $\geq 3$ ve üzeri hastalık), peroperatif dönemlere göre kullanılan kan bileşenlerinin çeşidi [(eritrosit süspansiyonu (ES), taze donmuş plazma (TDP) ve trombosit süspansiyonu (TS)] ve sayıSI kaydedildi. Hastalar preoperatif, intraoperatif ve postoperatif dönemde kan transfüzyonu yapılanlar ve yapılmayanlar olmak üzere 2 gruba ayrıldı.

\section{İstatistiksel Analiz}

İstatistiksel değerlendirme için Statistical Package for the Social Sciences (SPSS) 24.00 for windows paket programı kullanıldı. Veriler frekans (n), yüzde (\%) veya ortalama ve standart sapma (ortalama \pm SD) olarak belirtildi. Kategorik değişkenler Pearson's ki-kare testi kullanılarak karşılaştırıldı. Kan transfüzyonu üzerine bağımsız risk faktörleri ikili lojistik regresyon analizi ile incelendi. $p<0.05$ değeri istatistiksel olarak anlamlı kabul edildi.

\section{BULGULAR}

Kan transfüzyonu yapılan 245 hasta çalışmamıza dâhil edildi. Hastaların ortalama yaşı $58.09 \pm 16.11$ yıl ve cerrahi süresi $226.17 \pm 125.59 \mathrm{dk}$ olarak saptandı. Çalışma hastalarının demografik özellikleri, cerrahi bölümü-prosedürü, ASA skoru ve anestezi yöntemi Tablo 1'de gösterildi.

Hastalarımızın preoperatif muayenesinde \%37.1 ( $n=91$ )'inin anemik olduğu (ortalama preop- $\mathrm{Hb}$ : $11.56 \pm 1.94 \mathrm{~g} / \mathrm{dL}$ ), \%50.6 (n=124)'sının antikoagülan ilaç kullandığı ve \%78 ( $n=191)^{\prime}$ inin de ek hastalığı olduğu saptandı.

Preoperatif kan transfüzyonlarının preop-Hb değeri $\leq 7 \mathrm{~g} / \mathrm{dL}$ iken, 1 jinekoloji hastasına, 7.1-12.9 g/dL iken, 46 (6 KVC, 16 ortopedi, 14 jinekoloji, 3 obstetri, 7 genel cerrahi) ve $\geq 13 \mathrm{~g} / \mathrm{dL}$ iken ise 4 ( $3 \mathrm{KVC}$, 1 göğüs cerrahisi) hastaya yapıldığı saptandı ( $p=0.004$ ) (Tablo 2 ).

Tablo 1. Hastaların demografik özellikleri ve genel dağılımları (n,\%).

Kişi sayısı (n) Yüzde (\%)

\begin{tabular}{|c|c|c|}
\hline \multicolumn{3}{|l|}{ Yaş Grubu (yıl) } \\
\hline$\leq 39$ & 33 & 13.5 \\
\hline $40-64$ & 113 & 46.1 \\
\hline$\geq 65$ & 99 & 40.4 \\
\hline \multicolumn{3}{|l|}{ Cinsiyet } \\
\hline Kadın & 143 & 58.4 \\
\hline Erkek & 102 & 41.6 \\
\hline \multicolumn{3}{|l|}{ Cerrahi Bölüm } \\
\hline KVC & 85 & 34.7 \\
\hline Jinekoloji & 62 & 25.3 \\
\hline Ortopedi & 58 & 23.7 \\
\hline Genel Cerrahi & 21 & 8.6 \\
\hline Obstetri & 16 & 6.5 \\
\hline Diğer cerrahiler & 3 & 1.2 \\
\hline \multicolumn{3}{|l|}{ Cerrahi Prosedür } \\
\hline Acil & 48 & 19.6 \\
\hline Elektif & 197 & 80.4 \\
\hline \multicolumn{3}{|l|}{ ASA Skoru } \\
\hline 1 & 13 & 5.3 \\
\hline 2 & 78 & 31.8 \\
\hline 3 & 69 & 28.2 \\
\hline 4 & 85 & 34.7 \\
\hline \multicolumn{3}{|l|}{ Anestezi Yöntemi } \\
\hline Genel & 231 & 94.3 \\
\hline Rejyonal & 14 & 5.7 \\
\hline
\end{tabular}

KVC: Kalp ve damar cerrahisi, Diğer cerrahiler: Beyin ve göğüs cerrahisi, ASA: Amerikan Anesteziyologlar Derneği 
Tablo 2. Preoperatif transfüzyon uygulamasıyla ilişkili değişkenler.

\begin{tabular}{|c|c|c|c|}
\hline & $\begin{array}{l}\text { Preoperatif Transfüzyon Yok } \\
\qquad n=194(\%)\end{array}$ & $\begin{array}{l}\text { Preoperatif Transfüzyon Var } \\
\qquad \mathrm{n}=51(\%)\end{array}$ & p \\
\hline Yaş (yıl) (mean $\pm S D)$ & $57.78 \pm 15.83$ & $59.27 \pm 17.22$ & 0.558 \\
\hline Preop-Hb (g/dL) (mean $\pm S D)$ & $11.94 \pm 1.80$ & $10.15 \pm 1.86$ & $<0.001$ \\
\hline \multicolumn{4}{|l|}{ Yaş Grubu (yıl) } \\
\hline$\leq 39$ & $26(13.4)$ & $7(13.8)$ & 0.981 \\
\hline $40-64$ & 89 (45.9) & $24(47)$ & \\
\hline$\geq 65$ & 79 (40.7) & $20(39.2)$ & \\
\hline \multicolumn{4}{|l|}{ Cinsiyet } \\
\hline Kadın & $107(55.1)$ & $36(70.6)$ & 0.032 \\
\hline Erkek & $87(44.8)$ & $15(29.4)$ & \\
\hline \multicolumn{4}{|l|}{ Cerrahi Bölüm } \\
\hline KVC & 76 (39.2) & $9(17.6)$ & \\
\hline Ortopedi & $42(21.6)$ & $16(31.4)$ & 0.096 \\
\hline Jinekoloji & $47(24.2)$ & $15(29.4)$ & \\
\hline Obstetri & $13(6.7)$ & $3(5.9)$ & \\
\hline Genel Cerrahi & $14(7.2)$ & 7 (13.7) & \\
\hline Diğer cerrahiler & $2(1)$ & $1(1.9)$ & \\
\hline \multicolumn{4}{|l|}{ Cerrahi Prosedür } \\
\hline Acil & $36(18.5)$ & $12(23.5)$ & 0.270 \\
\hline Elektif & $158(81.4)$ & 39 (76.5) & \\
\hline \multicolumn{4}{|l|}{ ASA Skoru } \\
\hline 1 & $12(6.2)$ & $1(2)$ & 0.021 \\
\hline 2 & 61 (31.4) & $17(33.3)$ & \\
\hline 3 & $47(24.2)$ & $22(43.1)$ & \\
\hline 4 & 74 (38.1) & $11(21.5)$ & \\
\hline \multicolumn{4}{|l|}{ Hematolojik Patoloji } \\
\hline Yok & $136(70.1)$ & $11(21.6)$ & $<0.001$ \\
\hline Anemi & $51(26.3)$ & $40(78.4)$ & \\
\hline Diğerleri & $7(3.6)$ & $0(0)$ & \\
\hline \multicolumn{4}{|l|}{ Antikoagülan Kullanımı } \\
\hline Yok & $98(50.5)$ & $23(45)$ & 0.298 \\
\hline Var & 96 (49.5) & $28(55)$ & \\
\hline \multicolumn{4}{|l|}{ Ek Hastalık Sayısı } \\
\hline 0 & $43(22.1)$ & $11(21.6)$ & 0.571 \\
\hline 1 & $50(25.8)$ & $18(35.2)$ & \\
\hline 2 & $48(24.7)$ & 11 (21.6) & \\
\hline 3 & $53(27.3)$ & 11 (21.6) & \\
\hline Preop-Hb (g/dL) & & & 0.004 \\
\hline$\leq 7$ & 2 (1) & $1(2)$ & \\
\hline 7.1-12.9 & $132(68)$ & $46(90)$ & \\
\hline$\geq 13$ & $60(31)$ & $4(8)$ & \\
\hline
\end{tabular}

KVC: Kalp ve damar cerrahisi

Diğer cerrahiler: Beyin ve gögüus cerrahisi

ASA: Amerikan Anesteziyologlar Derneği

Diğerleri: Pansitopeni, trombositopeni 
Tablo 3. Intraoperatif transfüzyon uygulamasıyla ilişkili değişkenler.

\begin{tabular}{|c|c|c|c|}
\hline & $\begin{array}{l}\text { İntraoperatif Transfüzyon Yok } \\
n=143(\%)\end{array}$ & $\begin{array}{l}\text { Intraoperatif Transfüzyon Var } \\
n=102(\%)\end{array}$ & $\mathbf{p}$ \\
\hline Yaş (yıl) (mean $\pm S D)$ & $54.22 \pm 16.65$ & $63.53 \pm 13.64$ & $<0.001$ \\
\hline İntraop- $\mathrm{Hb}(\mathrm{g} / \mathrm{dL})$ & $11.10 \pm 1.57$ & $12.23 \pm 2.2$ & $<0.001$ \\
\hline Cerrahi süre (dk.) (mean $\pm S D)$ & $158.81 \pm 88.23$ & $320.61 \pm 108.30$ & $<0.001$ \\
\hline \multicolumn{4}{|l|}{ Yaş Grubu (yıl) } \\
\hline$\leq 39$ & $27(18.8)$ & $6(5.9)$ & 0.001 \\
\hline $40-64$ & 71 (49.6) & 42 (41.1) & \\
\hline$\geq 65$ & 45 (31.4) & $54(53)$ & \\
\hline \multicolumn{4}{|l|}{ Cinsiyet } \\
\hline Kadın & $113(79)$ & 30 (29.4) & $<0.001$ \\
\hline Erkek & 30 (20.9) & 72 (70.6) & \\
\hline \multicolumn{4}{|l|}{ Cerrahi Bölüm } \\
\hline KVC & $5(3.5)$ & $80(78.4)$ & $<0.001$ \\
\hline Ortopedi & 45 (31.5) & $13(12.7)$ & \\
\hline Jinekoloji & $59(41.2)$ & $3(2.9)$ & \\
\hline Obstetri & $14(9.8)$ & $2(2)$ & \\
\hline Genel Cerrahi & $19(13.3)$ & $2(2)$ & \\
\hline Diğer cerrahiler & $1(0.7)$ & $2(2)$ & \\
\hline \multicolumn{4}{|l|}{ Cerrahi Prosedür } \\
\hline Acil & $29(20.3)$ & 19 (18.6) & 0.439 \\
\hline Elektif & $114(79.7)$ & $83(81.4)$ & \\
\hline \multicolumn{4}{|l|}{ ASA Skoru } \\
\hline 1 & $13(9.1)$ & $0(0)$ & $<0.001$ \\
\hline 2 & $73(51)$ & $5(5)$ & \\
\hline 3 & 48 (33.6) & $21(20.5)$ & \\
\hline 4 & $9(6.3)$ & $76(74.5)$ & \\
\hline \multicolumn{4}{|l|}{ Anestezi Yöntemi } \\
\hline Genel & $130(91)$ & $101(99)$ & 0.007 \\
\hline Rejyonal & $13(9)$ & $1(1)$ & \\
\hline \multicolumn{4}{|l|}{ Hematolojik Patoloji } \\
\hline Yok & 77 (53.9) & 70 (68.6) & 0.026 \\
\hline Anemi & $63(44)$ & $28(27.4)$ & \\
\hline Diğerleri & $3(2.1)$ & $4(4)$ & \\
\hline \multicolumn{4}{|l|}{ Antikoagülan Kullanımı } \\
\hline Yok & 91 (63.6) & 30 (29.4) & $<0.001$ \\
\hline Var & $52(36.4)$ & $72(70.6)$ & \\
\hline \multicolumn{4}{|l|}{ Ek Hastalık Sayısı } \\
\hline 0 & 47 (32.9) & $7(6.9)$ & $<0.001$ \\
\hline 1 & $52(36.3)$ & 16 (15.7) & \\
\hline 2 & $26(18.2)$ & $33(32.3)$ & \\
\hline 3 & $18(12.6)$ & $46(45.1)$ & \\
\hline \multicolumn{4}{|l|}{ İntraop-Hb (g/dL) } \\
\hline$\leq 7$ & $1(0.7)$ & $2(2)$ & $<0.001$ \\
\hline 7.1-12.9 & $124(86.7)$ & $54(52.9)$ & \\
\hline$\geq 13$ & 18 (12.6) & $46(45.1)$ & \\
\hline
\end{tabular}

KVC: Kalp ve damar cerrahisi, Diğer cerrahiler: Beyin ve göğüs cerrahisi, ASA: Amerikan Anesteziyologlar Derneği, Diğerleri: Pansitopeni, trombositopeni 
Tablo 4. Postoperatif transfüzyon uygulamasıyla ilişkili değişkenler.

\begin{tabular}{|c|c|c|c|}
\hline & $\begin{array}{l}\text { Postoperatif Transfüzyon Yok } \\
n=19(\%)\end{array}$ & $\begin{array}{c}\text { Postoperatif Transfüzyon Var } \\
n=226(\%)\end{array}$ & p \\
\hline Yaş (yıl) (mean $\pm S D)$ & $54.63 \pm 15.60$ & $58.38 \pm 16.15$ & 0.330 \\
\hline Postop-Hb (g/dL) & $10.65 \pm 2.00$ & $10.45 \pm 1.26$ & 0.662 \\
\hline Cerrahi süre (dk.) (mean $\pm S D)$ & $178.42 \pm 123.85$ & $230.19 \pm 125.17$ & 0.084 \\
\hline \multicolumn{4}{|l|}{ Yaş Grubu (yıl) } \\
\hline$\leq 39$ & $3(15.8)$ & $30(13.3)$ & \multirow{3}{*}{0.716} \\
\hline $40-64$ & $10(52.6)$ & $103(45.6)$ & \\
\hline$\geq 65$ & $6(31.6)$ & $93(41.1)$ & \\
\hline \multicolumn{4}{|l|}{ Cinsiyet } \\
\hline Kadın & 11 (57.9) & $132(58.4)$ & \multirow[t]{2}{*}{0.574} \\
\hline Erkek & $8(42.1)$ & $94(41.6)$ & \\
\hline \multicolumn{4}{|l|}{ Cerrahi Bölüm } \\
\hline KVC & $5(26.3)$ & $80(35.4)$ & \multirow[t]{6}{*}{0.731} \\
\hline Ortopedi & $3(15.8)$ & $55(24.3)$ & \\
\hline Jinekoloji & $7(36.8)$ & $55(24.3)$ & \\
\hline Obstetri & $1(5.3)$ & $15(6.6)$ & \\
\hline Genel Cerrahi & $3(15.8)$ & $18(8)$ & \\
\hline Diğer cerrahiler & $0(0)$ & $3(1.3)$ & \\
\hline \multicolumn{4}{|l|}{ Cerrahi Prosedür } \\
\hline Acil & $8(42.1)$ & 40 (17.7) & \multirow{2}{*}{0.016} \\
\hline Elektif & 11 (57.9) & $186(82.3)$ & \\
\hline \multicolumn{4}{|l|}{ ASA Skoru } \\
\hline 1 & $0(0)$ & $13(5.8)$ & \multirow[t]{4}{*}{0.517} \\
\hline 2 & $8(42.1)$ & 70 (30.9) & \\
\hline 3 & $6(31.6)$ & $63(27.9)$ & \\
\hline 4 & $5(26.3)$ & $80(35.4)$ & \\
\hline \multicolumn{4}{|l|}{ Anestezi Yöntemi } \\
\hline Genel & 18 (94.7) & $213(94.2)$ & \multirow{2}{*}{0.930} \\
\hline Rejyonal & $1(5.3)$ & $13(5.8)$ & \\
\hline \multicolumn{4}{|l|}{ Hematolojik Patoloji } \\
\hline Yok & $6(31.6)$ & $141(62.4)$ & \multirow[t]{3}{*}{0.012} \\
\hline Anemi & $13(68.4)$ & $78(34.5)$ & \\
\hline Diğerleri & $0(0)$ & $7(3.1)$ & \\
\hline \multicolumn{4}{|l|}{ Antikoagülan Kullanımı } \\
\hline Yok & $13(68.4)$ & $108(47.8)$ & \multirow[t]{2}{*}{0.068} \\
\hline Var & $6(31.6)$ & $118(52.2)$ & \\
\hline \multicolumn{4}{|l|}{ Ek Hastalık Sayısı } \\
\hline 0 & $5(26.3)$ & 49 (21.7) & \multirow[t]{4}{*}{0.296} \\
\hline 1 & $8(42.1)$ & $60(26.5)$ & \\
\hline 2 & $4(26.1)$ & $55(26.3)$ & \\
\hline 3 & $2(10.5)$ & $62(27.4)$ & \\
\hline \multicolumn{4}{|l|}{ Postop-Hb (g/dL) } \\
\hline$\leq 7$ & $1(5.3)$ & $0(0)$ & \multirow[t]{3}{*}{0.002} \\
\hline $7.1-12.9$ & $17(89.5)$ & 219 (96.9) & \\
\hline$\geq 13$ & $1(5.2)$ & $7(3.1)$ & \\
\hline
\end{tabular}

KVC: Kalp ve damar cerrahisi

Diğer cerrahiler: Beyin ve göğüs cerrahisi

ASA: Amerikan Anesteziyologlar Derneği

Diğerleri: Pansitopeni, trombositopeni 
Tablo 5. Peroperatif kan transfüzyonuna etkileyen faktörlerinin analizi.

\begin{tabular}{|c|c|c|c|c|c|c|}
\hline & $\begin{array}{c}\text { PREOPERATIF DÖNEM } \\
\text { OR }(\% 95 \mathrm{CI})\end{array}$ & $\mathbf{p}$ & $\begin{array}{c}\text { INTRAOPERATIF } \\
\text { DÖNEM OR (\%95 CI) }\end{array}$ & $\mathbf{p}$ & $\begin{array}{c}\text { POSTOPERATIF } \\
\text { DÖNEM OR (\%95 Cl) }\end{array}$ & $\mathbf{p}$ \\
\hline Yaş & $1.017(0.984-1.051)$ & 0.327 & $0.978(0.941-1.017)$ & 0.258 & $1.001(0.96-1.044)$ & 0.955 \\
\hline Cinsiyet & $0.775(0.286-2.099)$ & 0.616 & $0.767(0.223-2.637)$ & 0.674 & $0.57(0.149-2.179)$ & 0.411 \\
\hline Cerrahi Bölüm & $1.019(0.696-1.492)$ & 0.924 & $0.46(0.246-0.857)$ & 0.014 & $1.039(0.619-1.743)$ & 0.886 \\
\hline Cerrahi Prosedür & $0.855(0.29-2.523)$ & 0.777 & $0.476(0.108-2.099)$ & 0.327 & $2.214(0.655-7.482)$ & 0.201 \\
\hline ASA Skoru & $1.126(0.493-2.574)$ & 0.779 & $4.608(1.816-11.691)$ & 0.001 & $0.646(0.22-1.899)$ & 0.427 \\
\hline Anestezi Yöntemi & $0.863(0.342-2.173)$ & 0.754 & $0.213(0.023-1.995)$ & 0.175 & $0.758(0.234-2.451)$ & 0.643 \\
\hline Cerrahi Süresi & $0.999(0.993-1.005)$ & 0.727 & $1.008(1.001-1.014)$ & 0.017 & $1.004(0.996-1.012)$ & 0.344 \\
\hline Antikoagülan Kullanımı Olanlar & $2.613(0.944-7.237)$ & 0.065 & $1.462(0.399-5.352)$ & 0.566 & $1.618(0.413-6.343)$ & 0.490 \\
\hline Ek Hastalığı Olanlar & $0.814(0.467-1.421)$ & 0.469 & $1.115(0.583-2.134)$ & 0.742 & $1.305(0.618-2.758)$ & 0.485 \\
\hline Hematolojik Patolojisi Anemi Olanlar & $10.258(3.884-27.088)$ & $<0.001$ & $3.228(1.006-10.352)$ & 0.049 & $0.252(0.076-0.835)$ & 0.024 \\
\hline
\end{tabular}

Preoperatif kan transfüzyon uygulamasıyla ilişkili değişkenler Tablo 2'de gösterildi. Preoperatif dönemde transfüze edilen toplam 232 ünite (Ü) kan bileşeninin 140 (\%60.3) Ü'sinin ES, 77 (\%33.2) Ü'sinin TDP, 15 (\%6.5) Ü'sinin de TS olduğu belirlendi.

Intraoperatif kan transfüzyonlarının intraop-Hb değeri $\leq 7 \mathrm{~g} / \mathrm{dL}$ olan 2 hastaya (1 KVC, 1 ortopedi), 7.112.9 g/dL iken, 54 (35 KVC, 11 ortopedi, 3 jinekoloji, 2 obstetri, 2 genel cerrahi, 1 beyin cerrahisi) ve $\geq 13$ g/dL iken, ise 46 (44 KVC, 1 ortopedi, 1 göğüs cerrahisi) hastaya yapıldığı saptandı $(p<0.001)$ (Tablo 3$)$. Intraoperatif kan transfüzyon uygulamasıyla ilişkili değişkenler Tablo 3'te gösterildi. İntraoperatif dönemde transfüze edilen toplam 938 Ü kan bileşeninin 403 (\%43) Ü'sinin ES, 388 (\%41.4) Ü'sinin TDP, 147 (\%15.6) Ü'sinin TS olduğu belirlendi.

Postoperatif kan transfüzyonlarının ise, postop- $\mathrm{Hb}$ değeri $\leq 7 \mathrm{~g} / \mathrm{dL}$ olan 1 hasta olduğu ve transfüzyon yapılmadığı, 7.1-12.9 g/dL iken, 219 (79 KVC, 55 ortopedi, 51 jinekoloji, 15 obstetri, 16 genel cerrahi, 2 göğüs cerrahisi, 1 beyin cerrahisi) ve $\geq 13 \mathrm{~g} / \mathrm{dL}$ iken, ise 7 (4 jinekoloji, 2 genel cerrahi, 1 KVC) hastaya yapıldığı saptandı ( $p=0.015$ ) (Tablo 4). Postoperatif kan transfüzyon uygulamasıyla ilişkili değişkenler Tablo 4'de gösterildi. Postoperatif dönemde transfüze edilen toplam 1299 Ü kan bileşeninin 664 (\%51.1) Ü'sinin ES, 488 (\%37.6) Ü'sinin TDP ve 147 (\%11.3) Ü'sinin TS olduğu görüldü.
Peroperatif kan transfüzyonuna etkileyen faktörler lojistik regresyon analiz ile incelendiğinde, preoperatif ve postoperatif dönemlerde yalnızca anemisi olanların olmayanlara göre transfüzyon gereksiniminin daha fazla olduğu görülürken, intraoperatif dönemde ise ASA skorundaki ve cerrahi süresindeki artışın yanında anemisi olanların olmayanlara göre transfüzyon gereksiniminin daha fazla olduğu ve cerrahi bölümlerden de KVC bölümünde genel cerrahiye göre daha fazla transfüzyon yapıldığı saptandı. Diğer bölümler arasında anlamlı bir farklılık yoktu. Diğer değişkenler ise bağımsız risk faktörü olarak belirlenmedi. Peroperatif kan transfüzyonuna etkileyen faktörlerin lojistik regresyon analiz sonuçları Tablo 5'te gösterildi.

\section{TARTIŞMA}

Çalışmamızda peroperatif anemisi olan 91 hastanın kan transfüzyonu gereksiniminin olmayanlara göre daha fazla olduğunu ve bu hastaların da 40 (\%43.9)'ına preoperatif, 28 (\%30.8)'ine intraoperatif ve 78 (\%85.7)'ine de postoperatif dönemde kan transfüzyon yapıldığını belirledik. Ayrıca toplamda kan transfüzyon sıklığımızın preoperatif $\% 20.8$, intraoperatif \%41.6 ve postoperatif dönemde de \%92.2 olduğunu saptadık.

Elektif cerrahi planlanan hastalarda preoperatif dönemde belirlenen ve en sık görülen hematolojik patolojinin anemi olduğu, anemi prevalansının, cerrahi 
tipine, hasta yaşına, eşlik eden morbiditelere ve aneminin tanımlanmasına ilişkin kriterlere bağlı olarak \%5-75 arasında değiştiği bildirilmiştir ${ }^{[22-27]}$. Illk olarak Benchmark ve OSTHEO çalışmalarından elde edilen verilere göre aynı prosedürler için opere edilen her 2 cins hastada, aynı miktardaki kan kaybındaki transfüzyon ihtiyacının, kadınlarda daha fazla olduğu bildirilmiştir. Bu veriler, "konvansiyonel" anemi tanımının kadın cerrahi hastalarının sınıflandırılmasında güvenilir olmayabileceğini göstermektedir [17-19,21]. Bu nedenle 2015 yılında Muñoz ve ark. ${ }^{[21]}$ anemi tanımının şu andaki cerrahi popülasyon için güvenilir olamayacağını, cerrahi hastalar için, "preoperatif anemi"nin yeniden tanımlanması ve "suboptimal preop-Hb konsantrasyonu" kavramının tanıtılmasının daha mantıklı olacağını bildirmişlerdir. Aynı zamanda fizyolojik olarak daha duyarlı olan tanımları beklerken, cinsiyetten bağımsız olarak preop- $\mathrm{Hb}<13 \mathrm{~g} / \mathrm{dL}$ ile başvuran hastaların anemik olarak düşünülmesi gerektiğini de belirtmişlerdir.

Transfüzyon eşikleri ve $\mathrm{Hb}$ hedeflerinin tartışıldığı çalışmalarda, $\mathrm{Hb}$ değeri $7 \mathrm{~g} / \mathrm{dL}$ 'nin altına düştüğünde transfüzyon yapılması ve transfüzyondan sonra 7-9 $\mathrm{g} / \mathrm{dL}^{\prime}$ lik hedef $\mathrm{Hb}$ değerlerinin titre edilmesi gerektiği bildirilmiştir. Ancak bu değerlerin hastaya ve klinik duruma özgü olduğu ve hastanın yandaş hastalıklarına bağlı olarak uygun transfüzyon hedeflerinin belirlenmesi gerektiği belirtilmiştir ${ }^{(28,29)}$. Birçok klinisyenin liberal bir transfüzyon stratejisini kullandığı da bilinmekle beraber en yeni NICE kılavuzları, kısıtlayıcı transfüzyon uygulamasını önermektedir [12-15,17,27-29].

Literatürde peroperatif transfüzyon kararını etkileyen faktörler arasında, preoperatif anemi varlığı, kadın cinsiyet, ileri yaş, hastanın fiziksel durumu, ek hastalıkları, kullanılmakta olan antikoagülan ve antiplatelet ilaçlar ve yüksek ASA skoru gibi klinik faktörlerin yanı sıra koagülasyon faktörleri, anestezi ve cerrahinin tipi, süresi, cerrahinin prosedürü ve kullanılan teknik yöntemler ile intraoperatif kanama miktarı olduğu bildirilmektedir ${ }^{[11-27,30,31]}$.

Preoperatif Hb konsantrasyonunun sıklıkla transfüz- yon riski taşıyan hastaları belirlemek için kullanıldığı ve perioperatif transfüzyonun güçlü bir prediktörü olduğu pekçok çalışmada gösterilmiştir ${ }^{[32-34]}$. Bununla birlikte, total kalça protezi (TKP) ameliyatı geçiren anemik olmayan birçok hasta için kan transfüzyonu gerektiğinden, preoperatif $\mathrm{Hb}$ düzeylerinin tüm transfüzyon gereksinimlerinin yalnızca sınırlı bir yüzdesini oluşturacağı da bildirilmiştir ${ }^{[34]}$. Pola ve ark. ${ }^{[35]}$ elektif TKP uygulanan, anemik ve anemik olmayan hastalarda perioperatif kan transfüzyonuyla ilişkili klinik faktörleri araştırdıkları çalışmada; perioperatif kan transfüzyonlarının \%75'inin preoperatif $\mathrm{Hb}$ konsantrasyonu $\geq 11 \mathrm{~g} / \mathrm{dL}$ olan bireylere yapıldığını vurgulamışlardır. Aynı çalışmada, 2 ya da daha fazla parametrenin (yaş, cinsiyet, hipertansiyon varlığı ve vücut kitle indeksi) kombinasyonunun kan transfüzyonu için önemli ölçüde artan bir risk ile ilişkili olduğu gösterilmiştir. Yüksel ve ark.'nın ${ }^{[36]}$ kadın hastalıkları ve doğum servislerinde kan bileşenleri kullanımına ilişkin durumu belirlemeye yönelik yaptıkları çalışmada, herhangi bir girişim gereken her 10 hastadan birisine herhangi bir kan bileşeni transfüzyonu yapıldığı bildirilmiştir. Van Straten ve ark.'nın ${ }^{[33]}$ preoperatif ve perioperatif bir veya daha fazla ES transfüzyonunu etkileyen faktörleri belirlemek amacıyla yaptıkları araştırmada, bağımsız risk faktörleri olarak: yaş, kadın cinsiyet, düşük vücut yüzey alanı, düşük sol ventrikül ejeksiyon fraksiyonu ( $<\% 35$ ), acil operasyon, önceki kalp ameliyatı, düşük preoperatif $\mathrm{Hb}$ ve kreatinin klirensi olduğu bildirilmiştir.

Çalışmamızda, düşük preop-Hb değeri, kadın cinsiyet, yüksek ASA skoru ve preoperatif anemisi olan hastalara transfüzyon yapılmış olması bulgularımızın diğer çalışmaların bulgularını doğrular nitelikte olduğunu düşündürmektedir. Kan transfüzyonunu etkileyen faktörleri regresyon analiziyle incelendiğimizde, preoperatif dönemde yalnızca preoperatif anemisi olanların olmayanlara göre transfüzyon gereksiniminin daha fazla olduğu görülmektedir. Dolayısıyla preoperatif aneminin, preoperatif dönemdeki transfüzyonlarının en büyük nedeni olduğunu söyleyebiliriz. Peroperatif anemisi olan 91 hastanın 40 (\%43.9)'ına preoperatif dönemde transfüzyon yapıl- 
mış olmasının nedenleri arasında, anemi tanımı için belirlediğimiz kriterlerin WHO kriterlerinden farklı olması, preop-Hb değeri: 7.1-12.9 g/dL iken, 46 (6 KVC, 16 ortopedi, 14 jinekoloji, 3 obstetri, 7 genel cerrahi) hastaya transfüzyon yapılmış olması, preoperatif kan transfüzyonu yapılan hastaların \%70.6'sını kadınların oluşturması, hastalarımızın \%78'inde ek hastalık olması ve transfüzyon eşik değerleri hakkında optimizasyon olmaması sayılabilir. Genel olarak kişisel farklılıklar olmakla beraber, kan transfüzyon için hekimler tarafından hâlen kabul edilen ve uygulanan $\mathrm{Hb}$ eşik değerinin $10 \mathrm{~g} / \mathrm{dL}$ düzeyinin tetikleyici olarak kabul edildiği görüldü. Kan transfüzyon eşiği olarak $7 \mathrm{~g} / \mathrm{dL} \mathrm{Hb}$ değerinin ancak kurumsal kültür değişikliği sağlanarak elde edilebileceği ve peroperatif kan transfüzyon sıklığının azalacağı düşüncesindeyiz. Ayrıca preoperatif değerlendirme aşamasında en azından elektif cerrahi olgularında preoperatif aneminin cerrahi girişim öncesi tedavisinin kuvvetli bir şekilde düşünülmesi gerektiğini, çünkü preoperatif aneminin belirlenmesinin kolay ve ucuz olduğunu unutmamak gerektiğini düşünmekteyiz.

Intraoperatif kan transfüzyon kararı genellikle tartışmalı olup, cerrah ve anestezi uzmanının farklı $\mathrm{Hb}$ konsantrasyonlarında yapılabileceğini savundukları ve genellikle de deneyimlerine dayanarak yaptıkları bir uygulamadır ${ }^{[10]}$. Her ne kadar optimal intraoperatif kan transfüzyon tetikleyicileri açık bir şekilde tanımlanmamışsa da kalp cerrahisi ve postoperatif ortopedi hastalarında 7-8 g/dL'lik bir Hb değerinin intraoperatif kan transfüzyonunu başlatmak için uygun olduğu belirtilmektedir ${ }^{[13,28]}$. Intraoperatif aneminin birinci basamak tedavisi, kan transfüzyon uygulamasıdır. Bu nedenle, hasta kan yönetimi (HKY) programları peroperatif gereksiz transfüzyonları önlemek için $\mathrm{Hb}^{\prime}$ nin preoperatif optimizasyonunun önemini vurgulamaktadır ${ }^{[10,14-17,21,25,26,37]}$. Başta kardiyak, ortopedik, jinekolojik ve kanser rezeksiyonu olmak üzere bazı cerrahilerde kan kaybının, cerrahinin rutin bir sonucu olduğu düşünülmektedir [21]. Frank ve ark. ${ }^{(33)}$ intraoperatif ve postoperatif dönemde en fazla kan transfüzyonunun KVC ve ortopedik cerrahilerde yapıldığını belirtmişlerdir. Balcı ve ark.'nın ${ }^{(39)}$ kalp cerrahisinde intraoperatif kan ürünü kullanım sıklığının hasta özelliklerine ve cerrahi tipine göre dağılımını araştırdıkları çalışmada, ileri yaş, kadın cinsiyet, düşük vücut kitle indeksi, düşük preop-Hb-hematokrit değeri ve uzun kros klemp/ kardiyo-pulmoner baypas/ameliyat sürelerinin transfüzyon miktarını artıran faktörler olduğu bildirilmiştir. TKP ameliyatı geçiren 606 hastada, genel ve spinal anestezinin karşılaştırıldığı bir çalışmada, spinal anestezi yapılan grupta intraoperatif kan kaybının $\% 25$, total kan kaybının \%38, intraoperatif transfüzyon gereksiniminin $\% 50$ ve postoperatif transfüzyon gereksinimin de $\% 20$ azaldığı bildirilmiştir ${ }^{[40]}$. Benzer şekilde genel anestezi uygulanan gebelerde spinal anestezi uygulananlara göre tahmini olarak daha fazla kan kaybı ve transfüzyon oranı bildirilmiştir ${ }^{[41]}$.

İntraoperatif kan transfüzyonunun ileri yaş, preoperatif anemisi olan, uzun süren cerrahiler, sıklıkla KVC ve ortopedi ameliyatları, ASA 3-4 risk grubu, genel anestezi altında opere olan, ek hastalığı ve antikoagülan kullanan hastalarda yapılmış olması bulgularımızın literatürle uyumlu olduğunu göstermektedir. Farklı olarak, intraoperatif kan transfüzyonu yapılan hastaların \%78.4 (80)'ünü KVC ameliyatları oluşturması ve bu hastaların da \%81 (65)'inin erkek cinsiyetten oluşması nedeniyle intraoperatif dönemde erkek hastalara daha fazla kan transfüzyonu yapıldığı kanısındayız. Preoperatif dönemde hastalarımızın \%50.6 ( $n=124$ )'sının antikoagülan ilaç kullandığını belirledik. Her ne kadar antikoagülan kullanımı regresyon analizine göre intraoperatif kan transfüzyon kararını etkiliyor gibi görünmese de özellikle intraoperatif dönemde transfüzyonu artırdığını gözledik. Özellikle KVC ameliyatlarında intraoperatif kan transfüzyonunun sıklıkla yapılmasının nedeni olarak, koroner rezervi sınırı olan bu hastaların akut anemiyi tolere etmesinin daha güç olması ve kanın oksijen taşıma kapasitesinin arttırılması amacıyla olduğu düşüncesindeyiz.

Elektif majör cerrahiden sonra postoperatif erken dönemde hastaların yaklaşık \%90'ının anemik olduğu gösterilmiştir. Bunun başlıca nedenleri arasında 
da, ameliyat öncesi aneminin varlığı, eşlik eden komorbiditeler, peroperatif kan kaybı, postoperatif dönemde yetersiz beslenme ve laboratuvar testleri için sık kan örneklemesi yapılması sayılmaktadır $(21,26,37)$. Kardiyak cerrahi sonrası yoğun bakıma kabul edilen hastalarda da anemi ile karşılaşma sıklığının oldukça yüksek olduğu ve bu aneminin, hastaların yaklaşık yarısında 50 güne kadar uzayabildiği bildirilmiş̧ir ${ }^{[42]}$. Spahn ve ark.'nın ${ }^{[43]}$ yaptığı çalışmada, TKP veya diz artroplastisi ve kalça kırığı ameliyatı geçiren hastalarda preoperatif anemi sıklığı \% 24-44 arasında değişirken, bu hastalarda postoperatif aneminin daha da yaygın olduğu (\%51-87) bildirilmiştir.

Postoperatif kan transfüzyonların \%82.3 oranında elektif cerrahilerde yapıldığını saptadığımız çalışmamızın sonuçlarının literatürle uyumlu olduğunu söyleyebiliriz. Postoperatif kan transfüzyonu yapılan ve yapılmayan hastaların ortalama postop-Hb değerlerinin $10 \mathrm{~g} / \mathrm{dL}$ civarında ve benzer olduğunu belirledik. Preoperatif ve intraoperatif dönemde düzeltilmemiş olan anemi ve kan kaybının, postop-Hb değerlerinde belirgin bir düşüşe ve bunun da hastaların önemli bir kısmında akut postoperatif anemi tedavisi için transfüzyon oranlarında artışa neden olduğu kanısındayız. Regresyon analizine baktığımızda, postoperatif dönemde yalnızca preoperatif anemisi olanların olmayanlara göre transfüzyon gereksiniminin daha fazla olduğu görülmektedir. Dolayısıyla preoperatif aneminin, postoperatif dönemdeki transfüzyonlarının da en sık nedeni olduğunu söyleyebiliriz. Postoperatif en çok KVC ve ortopedi vakalarına kan transfüzyonu yapılmış olmasının da yetersiz cerrahi hemostaz ve koagülasyon sistemindeki çeşitli anormalliklerden kaynaklanabilen yaygın bir cerrahi komplikasyon olduğu ve cerrahinin büyüklüğü ve hastaların eşlik eden komorbiditeleri nedeniyle olduğu düşüncesindeyiz.

\section{Çalışmanın sınırlayıcıları}

Çalışmamızı 3. basamak bir üniversite hastanesinde gerçekleştirmiş olmamız nedeniyle sonuçlarımız merkezimizin özelliklerini yansıtmaktadır ve bulgularımızın diğer merkezlere genelleştirilmesi sınırlı ola- bilir. Retrospektif bir çalışma olması, hasta sayımızın az olması, heterojen bir hasta popülasyonu olması, çoklu cerrah olan bir merkezde uygulanması, klinisyenlerin transfüzyon kararını etkileyen faktörlerin ne olduğunun sorgulanmamış olması, ameliyat sırasındaki kan kaybı miktarının ortaya konulmamış olmasının yanında hastaların peroperatif dönemdeki ISI takipleri, beslenme durumları, ejeksiyon fraksiyonla$\mathrm{rl}$, renal fonksiyonları ve reoperasyon gibi transfüzyon uygulamasını etkileyen pekçok faktörün değerlendirilmemiş olması diğer limitasyonlar arasında sayılabilir.

\section{SONUÇ}

Preoperatif kan transfüzyonlarının preop-Hb seviyesi ortalaması $10.15 \pm 1.86 \mathrm{~g} / \mathrm{dL}$ olan, kadın cinsiyet, ASA 2-3 risk grubu, anemi tanısı olan ve preop-Hb değeri 7.1-12.9 g/dL olanlarda; intraoperatif kan transfüzyonlarının intraop-Hb seviyesi ortalaması $12.23 \pm 2.2$ $\mathrm{g} / \mathrm{dL}$ olan, ileri yaş, erkek cinsiyet, uzun süren cerrahiler, KVC ve ortopedi cerrahileri, ASA 3-4 risk grubu, genel anestezi uygulanan, anemi tanısı olan, antikoagülan ilaç kullanımı ve yandaş hastalığı olan ve intraop-Hb değeri 7.1-12.9 g/dL olanlarda ve postoperatif kan transfüzyonların ise elektif şartlarda, anemi tanısı olan ve postop-Hb değeri 7.1-12.9 g/dL olanlarda daha fazla yapıldığı görülmüştür.

Kan transfüzyonu yapılıp yapılmayacağı kararı multifaktöryeldir. Genel olarak, cerrahi hastalarında kan transfüzyonunun aşırı yapıldığı, transfüzyon sınırları konusunda belirlenmiş protokoller bulunmadığı ve kanıta dayalı kılavuzlara uyma eksikliği olduğu görülmektedir. Bu profilden yola çıkarak hastane transfüzyon komitesi tarafından düzenlenen periyodik eğitimlerle ve çeşitli derneklerin de eğitimini sağladıkları "HKY" programları ile transfüzyon protokollerinin tüm hekimler tarafından güncellenmesinin; peroperatif transfüzyon uygulamasında davranış değişikliği sağlanarak gereksiz transfüzyonlardan kaçınmamıza, transfüzyonu konusunda optimizasyon sağlanmasına ve böylece hasta güvenliği açısından da daha az risk almamıza neden olacağı kanısındayız. Hekimlerin 
transfüzyonu azaltıcı yaklaşımları "iyi tıbbı uygulama" kültürü olarak benimsemeleri gerektiği ve önümüzdeki yıllarda HKY kavramının ülkemizde de yerleşmesi ve yaygınlaşmasının kaçınılmaz olacağı düşüncesindeyiz.

\section{KAYNAKLAR}

1. Ulusal Kan ve Kan Ürünleri Rehberi. I.Baskı. İstanbul 2011.

2. Hebert PC, Wells G, Martin C, Tweeddale M, Marshall $\mathrm{J}$, Blajchman $\mathrm{M}$, et al. Variation in red cell transfusion practice in the intensive care unit: A multicentre cohort study. Crit Care 1999;3:57-63. https://doi.org/10.1186/cc310

3. Manzini PM, Dall'Omo AM, D'Antico $S$, Valfrè $A$, Pendry $\mathrm{K}$, Wikman A, et al. Patient blood management knowledge and practice among clinicians from seven European university hospitals: a multicentre survey. Vox Sang. 2018;113:60-71. https://doi.org/10.1111/vox.12599

4. Use of blood products for elective surgery in 43 European hospitals. The Sanguis Study Group. Transfus Med. 1994;4:251-68. https://doi.org/10.1111/j.1365-3148.1994.tb00262.x

5. Baele P. Transfusion depends on the doctor, not on the patient: the SAnGUIS Study of Transfusion in Elective Surgery in Europe. Acta Anaesthesiol Belg. 1994;45: 3-4.

6. WHO. Haemoglobin concentrations for the diagnosis of anaemia and assessment of severity. Vitamin and Mineral Nutrition Information System. 2011. Geneva (Switzerland): World Health Organization; 2014.

7. Madjdpour C, Heindl V, Spahn DR. Risks, benefits, alternatives and indications of allogenic blood transfusions. Minerva Anestesiol. 2006;72:283-98.

8. Morisaki $\mathrm{H}$, Sibbald WJ. Tissue oxygen delivery and the microcirculation. Crit Care Clin. 2004;20:213-23.

https://doi.org/10.1016/j.ccc.2003.12.003

9. Butcher A, Richards T. Cornerstones of patient blood management in surgery. Transfus Med. 2018;28: 150-7.

https://doi.org/10.1111/tme.12476

10. American Society of Anesthesiologists Task Force on Perioperative Blood Transfusion and Adjuvant Therapies: Practice Guidelines for Perioperative Blood Transfusion and Adjuvant Therapies: An updated report by the American Society of Anesthesiologists Task Force on Perioperative Blood Transfusion and Adjuvant Therapies. Anesthesiology 2006;105:198208.

https://doi.org/10.1097/00000542-200607000-00030
11. Society of Thoracic Surgeons Blood Conservation Guideline Task Force, Ferraris VA, Brown JR, Despotis GJ, Hammon JW, Reece TB, Saha SP, Song HK, Clough ER, Society of Cardiovascular Anesthesiologists Special Task Force on Blood Transfusion, Shore-Lesserson LJ, Goodnough LT, Mazer CD, Shander A, Stafford-Smith $M$, Waters J, International Consortium for Evidence Based Perfusion, Baker RA, Dickinson TA, FitzGerald DJ, Likosky DS, Shann KG: 2011 update to the Society of Thoracic Surgeons and the Society of Cardiovascular Anesthesiologists blood conservation clinical practice guidelines. Ann Thorac Surg. 2011;91:944-82. https://doi.org/10.1016/j.athoracsur.2010.11.078

12. Blood Transfusion, NICE Guideline 24. National Clinical Guideline Centre (UK). London: National Institute for Health and Care Excellence (UK); 2015.

13. Hajjar LA, Vincent JL, Galas FR, Nakamura RE, Silva CM, Santos $\mathrm{MH}$, et al. Transfusion requirements after cardiac surgery: The TRACS randomized controlled trial. JAMA 2010;304:1559-67. https://doi.org/10.1001/jama.2010.1446

14. Eeles A, Baikady RR. Peri-operative blood management. Indian J Anaesth. 2017;61:456-62. https://doi.org/10.4103/ija.IJA_341_17

15. Kozek-Langenecker SA, Ahmed AB, Afshari A, Aldecoa C, Barauskas G, De Robertis E, et al. Management of severe perioperative bleeding: guidelines from the European Society of Anaesthesiology: first update 2016. European Journal of Anaesthesiology 2017;34: 332-95. https://doi.org/10.1097/EJA.0000000000000630

16. Klein AA, Arnold P, Bingham RM, Brohi K, Clark R, Collis $R$, et al. AAGBI guidelines: The use of blood components and their alternatives 2016. Anaesthesia. 2016;71:829-42. https://doi.org/10.1111/anae.13489

17. Rosencher N, Kerkkamp HE, Macheras G, Munuera LM, Menichella G, Barton DM, et al. Orthopedic Surgery Transfusion Hemoglobin European Overview (OSTHEO) study: blood management in elective knee and hip arthroplasty in Europe. Transfusion 2003;43:459-69. https://doi.org/10.1046/j.1537-2995.2003.00348.x

18. Gombotz H, Rehak PH, Shander A, Hofmann A. Blood use in elective surgery: the Austrian benchmark study. Transfusion 2007;47:1468-80. https://doi.org/10.1111/j.1537-2995.2007.01286.x

19. Gombotz H, Rehak PH, Shander A, Hofmann A. The second Austrian benchmark study for blood use in elective surgery: results and practice change. Transfusion. 2014;54:2646-57. https://doi.org/10.1111/trf.12687

20. Qian F, Osler TM, Eaton MP, et al. Variation of Blood Transfusion in Patients Undergoing Major Noncardiac 
Surgery. Ann Surg. 2012;1:13

21. Munoz M, Gomez-Ramirez S, Kozek-Langeneker S, Shander A, Richards T, Pavía J, et al. 'Fit to fly': overcoming barriers to preoperative haemoglobin optimization in surgical patients. Br J Anaesth. 2015;115:15-24. https://doi.org/10.1093/bja/aev165

22. Shander A, Knight K, Thurer R, Adamson J, Spence R. Prevalence and outcomes of anaemia in surgery: a systematic review of the literature. American Journal of Medicine 2004;116(Suppl. 7A):58-69.

https://doi.org/10.1016/j.amjmed.2003.12.013

23. Ania BJ, Suman VJ, Fairbanks VF, Rademacher DM, Melton LJ III: Incidence of anemia in older people: An epidemiologic study in a well defined population. J Am Geriatr Soc 1997;45:825-31. https://doi.org/10.1111/j.1532-5415.1997.tb01509.x

24. Musallam KM, Tamim HM, Richards T, Spahn DR, Rosendaal FR, Habbal A, et al. Preoperative anaemia and postoperative outcomes in non-cardiac surgery: a retrospective cohort study. Lancet 2011;378:1396407.

https://doi.org/10.1016/S0140-6736(11)61381-0

25. Munoz M, Gomez-Ramirez S, Campos A, Ruiz J, Liumbruno GM. Pre-operative anaemia: prevalence, consequences and approaches to management. Blood Transfusion 2015;13:370-9.

26. Lasocki S, Krauspe R, von Heymann C, Mezzacasa A, Chainey S, Spahn DR PREPARE: the prevalence of perioperative anaemia and need for patient blood management in elective orthopaedic surgery: a multicentre, observational study. Eur J Anaesthesiol. 2015;32: 160-7. https://doi.org/10.1097/EJA.0000000000000202

27. Kansagra AJ, Stefan MS. Preoperative anemia: Evaluation and treatment. Anesthesiol Clin. 2016;34: 127-41. https://doi.org/10.1016/j.anclin.2015.10.011

28. Carson JL, Terrin ML, Noveck H, Sanders DW, Chaitman $B R$, Rhoads $G G$, et al. Liberal or restrictive transfusion in high-risk patients after hip surgery. N Engl J Med. 2011;365:2453-6.

https://doi.org/10.1056/NEJMoa1012452

29. Boral LI, Bernard A, Hjorth T, Davenport D, Zhang D, Maclvor DC. How do I implement a more restrictive transfusion trigger of hemoglobin level of $7 \mathrm{~g} / \mathrm{dL}$ at my hospital? Transfusion. 2015;55:937-45. https://doi.org/10.1111/trf.12982

30. Douketis JD, Berger PB, Dunn AS, Jaffer AK, Spyropoulous $A C$, Becker RC, et al. The perioperative management of antithrombotic therapy: AmericanCollege of Chest Physicians evidence-based clinical practice guidelines (8th editions). Chest, 2012;133:299-339.

https://doi.org/10.1378/chest.08-0675
31. Mauermann WJ, Shilling AM, Zuo Z. A comparison of neuraxial block versus general anesthesia for elective total hip replacement: A meta-analysis. Anesth Analg. 2006;103:1018-25. https://doi.org/10.1213/01.ane.0000237267.75543.59

32. Salido JA, Marin LA, Gomez LA, Zorrilla P, Martinez C. Preoperative hemoglobin levels and the need for transfusion after prosthetic hip and knee surgery: analysis of predictive factors. J Bone Joint Surg Am. 2002;84:216-20. https://doi.org/10.2106/00004623-200202000-00008

33. van Straten $A H$, Kats $S$, Bekker MW, Verstappen F, ter Woorst JF, van Zundert AJ, et al. Risk factors for red blood cell transfusion after coronary artery bypass graft surgery. J Cardiothorac Vasc Anesth. 2010; 24:413-7. https://doi.org/10.1053/j.jvca.2010.01.001

34. Billote DB, Glisson SN, Green D, Wixson RL. A prospective, randomized study of preoperative autologous donation for hip replacement surgery. J Bone Joint Surg Am. 2002;84:1299-304. https://doi.org/10.2106/00004623-200208000-00003

35. Pola E, Papaleo P, Santoliquido A, Gasparini G, Aulisa L, De Santis E. Clinical factors associated with an increased risk of perioperative blood transfusion in nonanemic patients undergoing total hip arthroplasty. J Bone Joint Surg Am. 2004;86:57-61. https://doi.org/10.2106/00004623-200401000-00010

36. Yüksel H, Odabaşı AR, Kafkas S, Sezer DS, Kınaş GM, Kadıköylü G, Çetinşahin, et al. Kadın hastalıkları ve doğum servislerinde kan kullanımı. Adnan Menderes Üniversitesi Tıp Fakültesi Dergisi, 2006;7:7-11.

37. Muñoz M, Acheson AG, Auerbach M, Besser M, Habler $\mathrm{O}$, Kehlet $\mathrm{H}$, et al. International consensus statement on the perioperative management of anaemia and iron deficiency. Anaesthesia. 2017;72:233-47. https://doi.org/10.1111/anae.13773

38. Frank SM, Savage WJ, Rothschild JA, Rivers RJ, Ness PM, Paul SL, et al. Variability in blood and blood component utilization as assessed by an anesthesia information management system. Anesthesiology. 2012; 117:99-106. https://doi.org/10.1097/ALN.0b013e318255e550

39. Balcı E, Aykut A, Sert GS, Kemerci P, Koçulu R, Bölükbaşı $D$, et al. Kalp cerrahisinde bir yıllık intraoperatif kan ürünü kullanımı analizi: Hangi hastalarda? Hangi ameliyatlarda? Ne kadar? GKDA Derg 2016;22:62-9.

40. Maurer SG, Chen AL, Hiebert R, Pereira GC, Di Cesare $P E$. Comparison of outcomes of using spinal versus general anesthesia in total hip arthroplasty. Am J Orthop. Belle Mead NJ. 2007;36:E101-6.

41. Martin TC, Bell P, Ogunbiyi O. Comparison of general anaesthesia and spinal anaesthesia for caesarean sec- 
G. Küçükosman ve ark., Bir Üniversite Hastanesinde Peroperatif Kan Transfüzyon Uygulamalarını Etkileyen Faktörler

tion in Antigua and Barbuda. West Indian Med J. 2007;56:330-3.

42. Westenbrink BD, Kleijn L, de Boer RA, Tijssen JG, Warnica WJ, Baillot R, et al. Sustained postoperative anaemia is associated with an impaired outcome after coronary artery bypass graft surgery: insights from the
IMAGINE trial. Heart 2011;97:1590-56.

https://doi.org/10.1136/heartjnl-2011-300118

43. Spahn DR. Anemia and patient blood management in hip and knee surgery: a systematic review of the literature. Anesthesiology. 2010;113:482-95.

https://doi.org/10.1097/ALN.0b013e3181e08e97 